\title{
An Integrated Teaching Model for Factory Overhead Variance Analysis
}

\author{
David O’Bryan, Ph.D., CFE, CPA, CMA** \\ Professor of Accounting \\ Kelce College of Business \\ Pittsburg State University \\ Pittsburg, Kansas 66762 \\ Voice: (620) 235-4566 \\ Email: dobryan@pittstate.edu \\ Jeffrey J. Quirin, Ph.D., CMA \\ Professor \\ W. Frank Barton Distinguished Chair in Business \\ School of Accountancy \\ 342 Clinton Hall \\ Barton College of Business \\ Wichita State University \\ Wichita, Kansas 67260 \\ Voice: (316) 978-6258 \\ Fax: (316) 978-3660 \\ Email: jeffrey.quirin@wichita.edu
}

Jenny O'Bryan

Graduate Student in Accountancy

University of Tulsa

800 S. Tucker Drive

Tulsa, OK 74104

Voice: (620) 238-0429

Email: jd0611@utulsa.edu

**Contact Author 


\title{
An Integrated Teaching Model for Factory Overhead Variance Analysis
}

\begin{abstract}
The determination of factory overhead variances is often a challenging topic for students in managerial / cost accounting. This paper presents a four-column teaching model that integrates all of the factory overhead variances into a single model and only requires students to calculate three key values. This model can be useful for faculty members who may be searching for an alternative way to teach this topic as well as students who are having difficulty learning this material.
\end{abstract}




\title{
An Integrated Teaching Model for Factory Overhead Variance Analysis
}

\author{
Introduction
}

One of the more challenging topics in managerial / cost accounting for students and teachers alike is factory overhead variance analysis. Some textbooks use a three-column model with separate analyses for variable overhead variances and fixed overhead variances (e.g., Lanen et al, 2017). Horngren et al. (2015) utilize a four-column with separate analyses for variable and fixed overhead variances.

The purpose of this teaching note is to present an integrated, four-column teaching model for factory overhead variance analysis that incorporates all variable and fixed factory overhead variances into a single model. For the typical textbook problem, the model only requires students to calculate three missing values so it has the potential to make a confusing topic more accessible to the average student.

\section{Prerequisite Knowledge}

Analysis of factory overhead variances typically follows coverage of fixed versus variable costs, standard costing systems, calculation of applied factory overhead rates, and actual versus applied factory overhead. The conceptual model presented in this paper assumes students have already covered these topics.

\section{The Conceptual Model}

The conceptual model is presented in Figure 1. The model consists of four columns and three rows. The four columns are, from left-to-right, actual overhead costs, flexible budget based on inputs, flexible budget based on outputs, and applied overhead costs. In this context, inputs refers to the actual units of the overhead allocation base used during the period. Outputs refers to 
the standard units of the overhead allocation base allowed for the actual units produced during the period.

The three rows are variable overhead costs, fixed overhead costs, and total overhead costs. As you move from left-to-right larger (smaller) numbers indicate favorable (unfavorable) variances, which is a useful aid for students who struggle with the concept of favorable versus unfavorable variances.

\section{[Insert Figure 1 About Here]}

There are only three key values that need to be determined in order to calculate all of the factory overhead variances. These key values are referenced as items (1) through (3) in Figure 1. Item (1) is the budgeted variable factory overhead application rate multiplied by the actual number of units of the factory overhead application base utilized during the period.

Item (2) is the budgeted variable factory overhead application rate multiplied by the standard units of factory overhead application base allowed for the actual number of units produced during the period. As shown in Figure 1, this item appears in both columns three and four. The amount of variable factory overhead in the flexible budget based on outputs is exactly the same as the amount of variable factory overhead applied.

Item (3) is the amount of fixed factory overhead applied during the period. It is the fixed factory overhead application rate multiplied by the standard units of factory overhead application base allowed for the actual number of units produced during the period.

Once the conceptual model in Figure 1 is completed all of the factory overhead variances can be calculated. The differences between columns one and two represent the variable and fixed overhead spending variances. The difference between columns two and three is the variable efficiency variance, while the difference between columns three and four is the fixed factory 
overhead production - volume variance. Comparing column one to column three results in the variable and fixed overhead flexible budget variances. Lastly, the difference between columns one and four is the over (under) applied variable and fixed overhead.

\section{Numerical Example}

A numerical example to apply the conception model appears in Figure 2. The context for this problem is a contractor producing wing parts for an aircraft. The company uses a standard costing system and applies factory overhead based upon the standard number of hours of laser cutting per wing part. The flexible budget cost equation is total budgeted factory overhead costs equals fixed costs of $\$ 1,800,000$ plus $\$ 200$ per standard laser cutting time per wing part. The budgeted production and sales was 5,000 wing parts which would require $(5,000$ wing parts times 1.5 standard laser cutting hour per wing part) 7,500 standard laser cutting hours. Consequently, the fixed factory overhead application rate is $(\$ 1,800,000$ divided by 7,500 standard laser cutting hours) \$240 per laser cutting hour.

[Insert Figure 2 About Here]

Figure 2 shows the calculation of the three key values needed to determine all of the factory overhead variances for this scenario. Once those values are determined the spending, efficiency and volume variances drop out of the model by comparing column one to column two, column two to column three, and column three to column four, respectively. The flexible budget variance falls out of the model as the difference between columns one and three. Finally, the over- or under-applied overhead is the difference between column one and column four. As one moves from left-to-right larger (smaller) numbers indicate favorable (unfavorable) variances. Likewise, a larger (smaller) number on the right indicates over (under) applied factory overhead. 


\section{Conclusion}

Students often struggle with the calculation of factory overhead variances. And because students struggle with the topic, faculty may find this to be a challenging topic for instruction.

The integrated, four-column teaching model presented in this paper provides students and faculty with an alternative method to learn and teach this topic. 


\section{Figure 1}

\section{Conceptual Overview of Factory Overhead Variance Analysis Model}

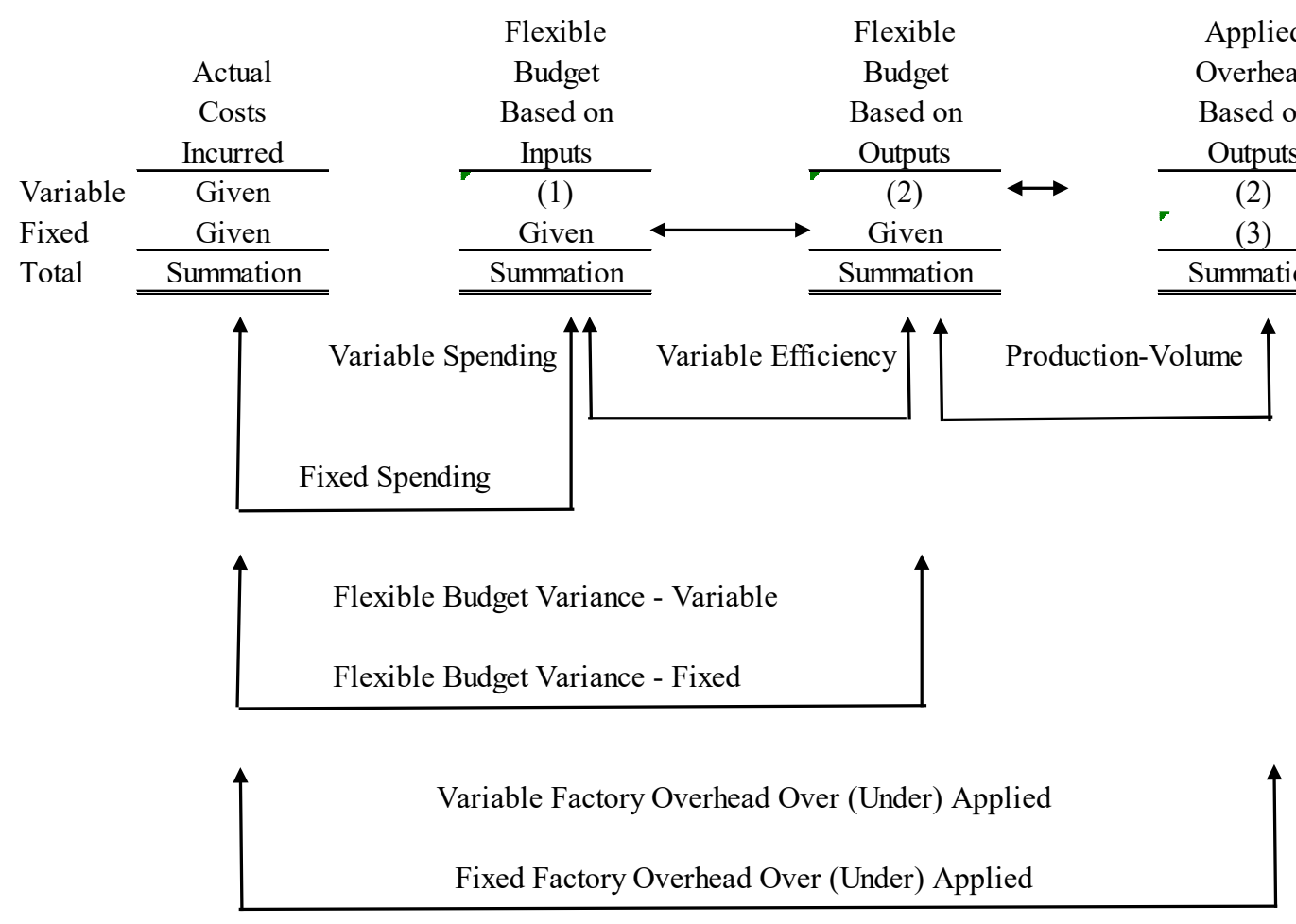

Key Values:

(1) Budgeted variable factory overhead application rate * Actual number of inputs utilized during the period.

(2) Budgeted variable factory overhead application rate * Standard units based on actual output produced during the period.

(3) Budgeted fixed factory overhead application rate * Standard units based on actual output produced during the period. 


\section{Figure 2 \\ Numerical Example of Factory Overhead Variance Analysis Model}

Budgeted Variable Overhead Rate

Budgeted Fixed Overhead Rate

Budget Laser-Cutting Time per Wing Part

Budgeted Production and Sales for May

Budgeted Fixed Overhead Costs for May

Actual Wing Parts Produced and Sold

Actual Laser-Cutting Hours Used

Actual Variable Overhead Costs

Actual Fixed Overhead Costs
$\$ 200$ per laser cutting hour

$\$ 240$ per laser cutting hour

1.5 hours

5,000 parts

$\$ 1,800,000$

4,800 parts

8,400 hours

$\$ 1,478,400$

$\$ 1,832,200$

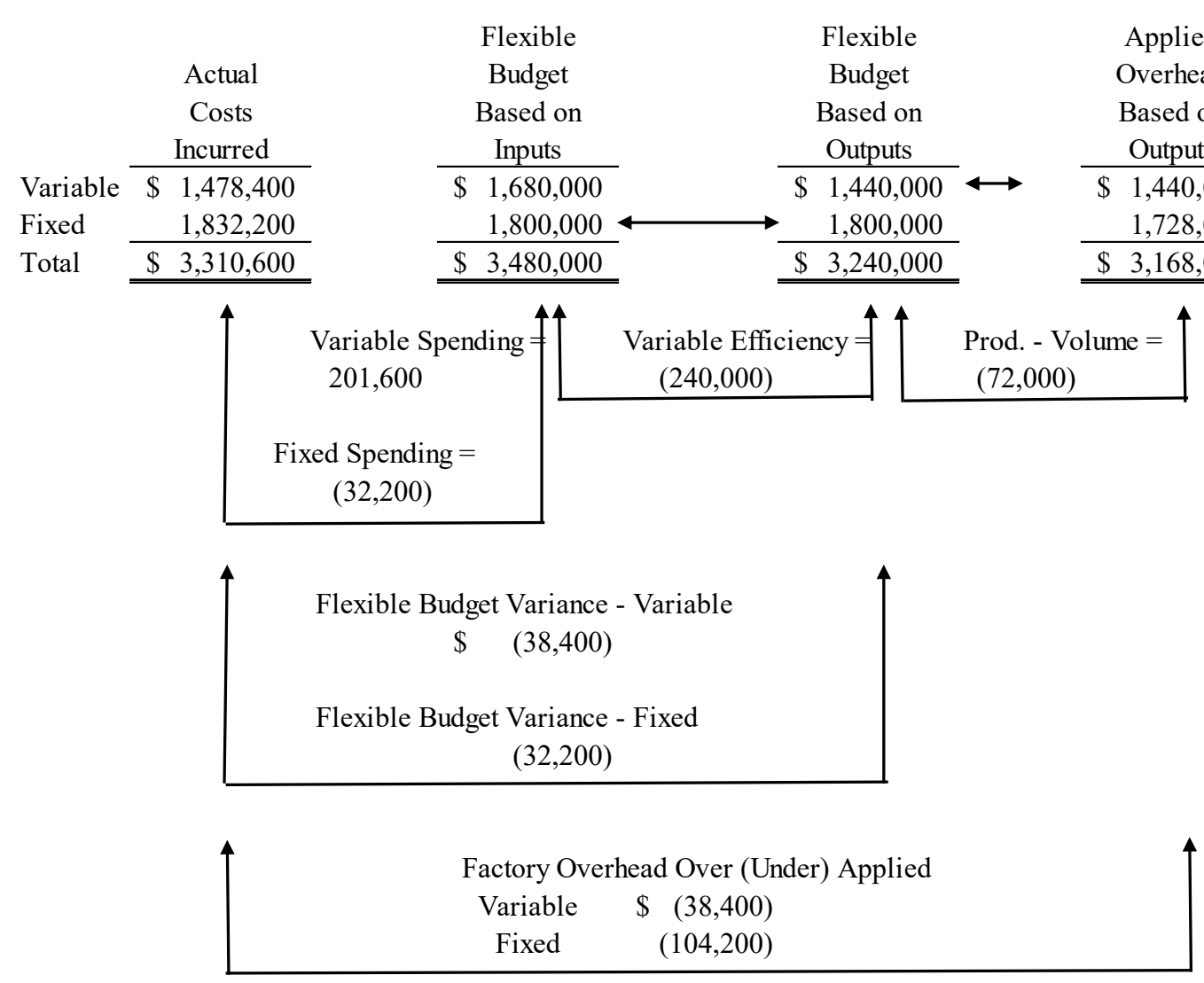

Key Values:

(1) $\$ 200$ per laser cutting hour *8,400 laser cutting hours.

(2) \$200 per laser cutting hour $* 4,800$ actual wing parts produced $* 1.5$ standard laser cutting hours per wing part.

(3) \$240 per laser cutting hour * 4,800 actual wing parts produced $* 1.5$ standard laser cutting hours per wing part. 


\section{References}

Horngren, C., S. Datar, and M. Rajan. 2015. Cost Accounting: A Managerial Emphasis. Pearson Education, Inc. Upper Saddle River, NJ.

Lanen, W., S. Anderson, and M. Maher. 2017. Fundamentals of Cost Accounting. The McGrawHill Companies, Inc. New York, NY. 